\title{
A PERCEPÇÃO DOS FUTUROS PROFESSORES DE EDUCAÇÃO FÍSICA SOBRE A PREPARAÇÃO NO TRABALHO COM PESSOAS COM DEFICIÊNCIA
}

\author{
Vickele Sobreira \\ Universidade Federal do Triângulo Mineiro, Uberaba ,Minas Gerais, Brasil. \\ Solange Rodovalho Lima \\ Universidade Federal de Uberlândia, Uberlândia, Minas Gerais, Brasil. \\ Vilma Lení Nista-Piccolo \\ Universidade de Sorocaba, Sorocaba, São Paulo, Brasil.
}

\begin{abstract}
Resumo: Nesse estudo buscamos identificar aspectos que influenciam positiva e negativamente numa futura atuação do professor de Educação Física, no que concerne às percepções de acadêmicos a respeito do preparo no desenvolvimento de atividades práticas desenvolvidas em um projeto de extensão que atende pessoas com deficiência. Foi possível perceber que há um distanciamento entre o que é trabalhado nas disciplinas curriculares e as práticas vivenciadas na formação inicial. A descontextualização da estrutura curricular do curso, evidenciada nos discursos dos futuros professores, aponta a necessidade de reflexões a respeito de uma reorganização do currículo dos cursos de formação de professores da área e as suas implicações na atuação profissional.
\end{abstract}

Palavras-chave: Formação de professores. Cursos de Licenciatura. Atuação profissional.

\section{Introdução}

A formação docente tem sido debatida nos últimos anos em eventos específicos, em estudos de grupos dessa natureza, divulgados em pesquisas realizadas na área da Educação e da Educação Física.

Ao nos depararmos com o panorama atual da vida profissional dos docentes, é possível destacar algumas diferenças com relação a outros tempos. As situações vivenciadas em seu trabalho podem ser atualmente mais difíceis de serem enfrentadas como o comportamento inadequado dos alunos, o descaso de governos e direções com o ambiente educacional, e o desinteresse pelo conhecimento pedagógico atualizado frente às insatisfações com seu trabalho; no entanto, há questões que norteiam o ensino e a aprendizagem que eles têm acesso que foram facilitadas no cotidiano do professor, como diretrizes educacionais sugeridas, pela grande variedade de livros didáticos existentes, pelos diversos cursos oferecidos aos professores, eventos específicos, além da facilidade de buscar novas informações via internet. Mas, essas diferenças positivas não trouxeram mudanças significativas na maneira como o professor exerce sua função e mesmo no funcionamento das instituições de ensino (ROLDÃO, 1999).

Os currículos empregados nos cursos de licenciatura sofreram modificações a partir de novas diretrizes que apontam os caminhos desenhados para formação de professores, permitindo maior flexibilização do mesmo. Essas alterações não se mostraram ainda eficazes para as ações docentes, pois, muitas vezes, são realizadas de acordo com as disponibilidades 
das instituições de ensino superior, e pouco relacionadas à qualidade de formação e ensino desses futuros docentes.

Exemplifique-se com o ponto de vista de que as políticas educacionais visam tender às demandas do mercado de trabalho, tanto nos países industrializados quanto nos que se encontram em processo de desenvolvimento. Ainda que se trate de uma visão presente no imaginário educacional nesses países, há que se perguntar: os diferentes mercados se mostram convergentes? Provavelmente não. (MOREIRA, 2013, p. 73-74)

De acordo com Formosinho e Machado (2008) apesar das exigências dos currículos educacionais visarem uma adaptação às necessidades sociais do contexto em que se desenvolvem, é notável a presença de uma abordagem pedagógica que aplica um ensino universal e impessoal dos conteúdos, submetendo alunos diferentes ao mesmo procedimento metodológico nos processos de sua aprendizagem. Além disso, a postura individualista, isolada e privatista de alguns docentes confere ao modelo de educação uma característica transmissiva de conhecimento (FORMOSINHO; MACHADO, 2008).

Essa noção de que o conhecimento pode ser transmitido e massificado, pode gerar a ideia de que um conteúdo "possivelmente aprendido" pode ser aplicado em todos os contextos nos quais vão atuar, reforçando ações reprodutivistas e repetitivas em suas formas de ensinar, sem se preocuparem com a função educativa e transformadora.

Dessa forma é necessário focar em aspectos do currículo de formação de professores que possam diminuir esse distanciamento que existe entre a formação inicial e a prática pedagógica do professor.

A apropriação de conhecimentos científicos e pedagógicos pelos futuros profissionais deve permitir a leitura dos problemas em situações reais, visando a busca de soluções para o contexto em que vivem. Não pautado num modelo aplicacionista do conhecimento, que dissocia a pesquisa da formação e da atuação profissional, mas apoiado numa integração que promova a reflexão para a ação. (MOREIRA; NISTA-PICCOLO, 2010, p.77)

Sabemos que as diretrizes curriculares que norteiam a organização dos currículos de licenciatura estabelecem algumas padronizações que deveriam compor o leque de necessidades para a formação básica do futuro professor. Dentre elas podemos destacar os estágios obrigatórios, as práticas de ensino, disciplinas específicas de cunho científico-culturais que podem fornecer subsídios para uma atuação adequada desse profissional, além de outras atividades complementares (BRASIL, 2002). E todos esses quesitos precisam estar articulados em unidades de conhecimento específico (dimensões culturais do movimento humano, técnico instrumental, didático-pedagógica) e ampliado (relação ser humanosociedade, biológica do corpo humano, produção do conhecimento científico e tecnológico), com as suas respectivas denominações, ementas e cargas horárias coerentes com a formação do profissional que se deseja ter (FRAUCHES, 2008).

Mas, para Mello (2000) a situação dos cursos de formação de professores é inversamente proporcional à situação da realidade profissional, já que alguns professores recebem uma formação deficitária no aspecto pedagógico, o que implica num despreparo para enfrentarem problemas de aprendizagem de seus alunos, dificuldades nas escolhas de conteúdos, nos métodos e estratégias a serem definidos para aquele contexto, e isso se dá em 
qualquer nível de ensino escolar. Essa é a realidade diagnosticada em diversas especificidades de ação docente, não sendo um problema isolado das áreas de Humanas, Biológicas ou Exatas (MELLO, 2000).

A formação de professores tem sido constituída por duas grandes partes: a disciplinar que corresponde ao acúmulo de conteúdos sobre diferentes conhecimentos, distribuídos em disciplinas; e a prática pedagógica relacionada à ação docente, que deve ser embasada cientificamente, com práticas especificamente planejadas, estruturadas e organizadas a partir das teorias e métodos presentes nos estudos voltados para o âmbito educacional. Entretanto, a não integração dessas partes que compõem a estrutura curricular tem repercutido numa fragilidade na formação de professores, pois há uma tendência na maioria dos cursos de licenciatura em priorizar os saberes promovidos pelos conteúdos essencialmente teóricos em detrimento das práticas pedagógicas (GAMA; TERRAZZAN, 2013).

É preciso que aconteça uma relação constante entre os conhecimentos construídos nas disciplinas e a aplicação utilização dos mesmos nas intervenções profissionais, permitindo aos acadêmicos a verdadeira noção da práxis.

Os cursos de licenciatura em Educação Física podem buscar essa relação de forma harmoniosa, desenvolvendo conteúdos a serem aprendidos durante a formação, visando à atuação docente, por meio de vivências reais das práticas pedagógicas, previstas nos seus currículos.

Mas, não diferente de qualquer outra área de conhecimento, a formação de professores de Educação Física também se mostra defasada frente às necessidades de mudanças na atuação desse profissional, inclusive aquelas que estão vinculadas à formação inicial desses professores. "O ensino, particularmente na perspectiva da formação profissional, requer que se estimulem os alunos a aprender e construir conhecimentos coerentes com sua própria prática" (ARAÚJO, 2007, p. 41). Um ensino que deve buscar construções e transformações no processo de aprendizagem dos alunos e melhorias na ação docente em Educação Física:

Em nosso entendimento, professores competentes preocupam-se com o aprendizado dos alunos, conseguem avaliar até que ponto eles compreenderam o que foi ensinado. São professores atualizados com o ato de ensinar que não oferecem conteúdos prontos, proporcionam oportunidades para seus alunos construírem seus próprios conhecimentos, favorecendo o sentido da autopoiesis (NISTA-PICCOLO; MOREIRA, 2012, p. 42-43).

Corroboramos a tese de Moreira e Tojal (2009, p. 128) quando esclarecem seus pontos de vista sobre a preparação do professor de Educação Física, expressando que:

[...] a preparação profissional para exercer a função de professor deveria ocorrer num ambiente em que os conhecimentos sobre o ser humano, suas capacidades, necessidades, possibilidades e desejos possam ser analisados sob diferentes aspectos, uma preparação estritamente acadêmica e profissional.

Complementando essa ideia, reforçamos a necessidade de um olhar mais aprimorado sobre a formação, destacando que

O processo de formação de professores é complexo, mas deve permitir um diálogo com a atuação desse profissional. Isto quer dizer que ao tomarem contato com os conhecimentos científicos e pedagógicos, os graduandos, futuros profissionais, devem ter ciência dos problemas reais que poderão 
enfrentar na aplicação desse conhecimentos. Sem dissociar a formação da própria atuação, mas integrando reflexões sobre essa ação. (NISTAPICCOLO, 2010, p. 119)

Por isso, é necessário que repensemos como esse profissional está sendo formado e, principalmente, como ele está estabelecendo a relação, indissociável, entre a formação inicial e sua futura atuação profissional, na tentativa de buscarmos caminhos mais objetivos na melhoria da formação do professor de Educação Física.

Como característica principal definidora da preparação segura de um profissional de educação física, é desejável que, além de entender a individualidade do ser humano, tenha mesmo as condições e os conhecimentos necessários para identificar formas, meios, materiais e equipamentos que lhe favoreçam ser suficientemente capaz de orientar, instrumentalizar e auxiliar os indivíduos, para que, por si sós, consigam alcançar os objetivos que se propõem. (TOJAL, 2006, p. 247-248)

Entendemos que um acadêmico formado em curso de licenciatura, precisa ter clareza sobre o ato de ensinar, função de professor, para atuar no mercado de trabalho.

Com base em todo o exposto, trazemos nesse estudo dados referentes às percepções dos acadêmicos, de um curso de licenciatura em Educação Física, sobre sua atuação com a Educação Especial. Foram analisadas possíveis inseguranças em sua futura ação docente, identificando as bases teóricas e práticas específicas em sua formação, e ainda, as divergências existentes sobre o conhecimento fundamental para uma aplicação na atuação profissional, gerando reflexões sobre formação de professores e organização curricular.

\section{Procedimentos Metodológicos}

Por meio de uma abordagem qualitativa, essa pesquisa, autorizada pelo Comitê de Ética e Pesquisa sob o número 2565, investigou como os alunos de um curso de licenciatura em Educação Física, de uma Universidade localizada no Triângulo Mineiro, percebem a consistência de sua formação para uma futura ação profissional no que concerne ao desenvolvimento de atividades voltadas para pessoas com deficiência.

Utilizamos como técnica de coleta de dados uma entrevista semiestruturada, desenvolvida a partir da autorização dos acadêmicos com consentimento de gravação em áudio e assinatura do TCLE. Foram entrevistados 17 acadêmicos que estavam diretamente envolvidos num projeto de extensão específico para esse fim, desenvolvido há 32 anos pela Universidade, o qual oferece atividades variadas que visam à melhoria da saúde e da qualidade de vida de pessoas com deficiência.

Dos 17 acadêmicos entrevistados, 04 (quatro) são monitores do projeto, 05 (cinco) são alunos/observadores da prática de formação e 08 (oito) são alunos/ estagiários que intervêm diretamente, assistidos pelos monitores e professores orientadores, com atividades para pessoas com deficiência, matriculadas no projeto de extensão.

A entrevista, composta por três perguntas norteadoras, visou investigar a importância dessa atividade prática na formação inicial e como conhecimento para a futura atuação profissional desses acadêmicos, por meio das seguintes indagações: 1) Qual sua opinião a respeito da prática pedagógica vivenciada? Destaque pontos positivos e negativos. 2) Qual o 
seu preparo para as intervenções realizadas? 3) Qual a contribuição dessa prática pedagógica para sua formação profissional/pessoal?

Após a transcrição das respostas dos voluntários, o procedimento da análise interpretativa se deu por meio da elaboração de categorias criadas a partir das unidades de significado que foram elencadas dos discursos dos sujeitos, conforme propõem Laville e Dione (1999), caracterizando-se em três etapas: descrição, redução e interpretação.

\section{Resultados e Discussão}

As respostas dos voluntários foram organizadas nos quadros que seguem abaixo, de acordo com as categorias identificadas nas análises das respostas, sendo as letras "“O" referentes aos Observadores, "E" representando os Estagiários e "M" para a apresentação dos Monitores. Os números que acompanham as letras são apenas para diferenciação dos voluntários que participaram da pesquisa.

Com relação ao primeiro questionamento feito aos acadêmicos, "Qual a sua opinião a respeito da prática pedagógica vivenciada?", as respostas geraram subcategorias, sendo nos pontos positivos: aprimoramento pessoal, experiência fundamental na formação profissional. $\mathrm{Na}$ categoria pontos negativos apareceram os subitens: desorganização do projeto, insegurança na realização das atividades, falta de conhecimento prévio para atuar com os alunos.

Quadro 1: Opinião dos acadêmicos a respeito da prática pedagógica vivenciada.

\begin{tabular}{|c|c|c|c|c|c|c|c|c|c|c|c|c|c|c|c|c|c|}
\hline \multicolumn{18}{|c|}{ Categoria: PONTOS POSITIVOS } \\
\hline \multirow[t]{2}{*}{ SUBCATEGORIAS } & \multicolumn{17}{|c|}{ VOLUNTÁRIOS } \\
\hline & $\begin{array}{l}\mathbf{O} \\
1\end{array}$ & $\begin{array}{l}\mathbf{O} \\
\mathbf{2}\end{array}$ & $\begin{array}{l}\mathbf{O} \\
\mathbf{3}\end{array}$ & $\begin{array}{l}\mathbf{O} \\
4\end{array}$ & $\begin{array}{l}\mathbf{O} \\
5\end{array}$ & $\begin{array}{l}\mathbf{E} \\
\mathbf{1}\end{array}$ & $\begin{array}{l}\mathbf{E} \\
2\end{array}$ & $\begin{array}{l}\mathbf{E} \\
\mathbf{3}\end{array}$ & $\begin{array}{l}E \\
4\end{array}$ & $\begin{array}{l}\mathbf{E} \\
\mathbf{5}\end{array}$ & $\begin{array}{l}\mathbf{E} \\
\mathbf{6}\end{array}$ & $\begin{array}{l}\mathbf{E} \\
7\end{array}$ & $\begin{array}{l}\mathbf{E} \\
8\end{array}$ & $\begin{array}{c}\mathbf{M} \\
1\end{array}$ & $\begin{array}{c}\mathbf{M} \\
\mathbf{2}\end{array}$ & $\begin{array}{l}\mathbf{M} \\
\mathbf{3}\end{array}$ & $\begin{array}{c}M \\
4\end{array}$ \\
\hline Aprimoramento pessoal & $\mathrm{X}$ & $\mathrm{X}$ & $\mathrm{X}$ & $\mathrm{X}$ & $\mathrm{X}$ & $\mathrm{X}$ & $\mathrm{X}$ & $\mathrm{X}$ & $\mathrm{X}$ & $\mathrm{X}$ & $\mathrm{X}$ & $\mathrm{X}$ & $\mathrm{X}$ & & & & \\
\hline $\begin{array}{l}\text { Experiência fundamental } \\
\text { para a formação }\end{array}$ & $\mathrm{X}$ & $\mathrm{X}$ & & & $\mathrm{X}$ & $\mathrm{X}$ & $\mathrm{X}$ & $\mathrm{X}$ & $\mathrm{X}$ & $\mathrm{X}$ & $\mathrm{X}$ & $\mathrm{X}$ & $\mathrm{X}$ & $\mathrm{X}$ & $\mathrm{X}$ & $\mathrm{X}$ & $\mathrm{X}$ \\
\hline \multicolumn{18}{|c|}{ Categoria: PONTOS NEGATIVOS } \\
\hline SUBCATEGORIAS & \multicolumn{17}{|c|}{ VOLUNTÁRIOS } \\
\hline & $\begin{array}{l}\mathbf{O} \\
1\end{array}$ & $\begin{array}{l}\mathbf{O} \\
\mathbf{2}\end{array}$ & $\begin{array}{l}\mathbf{O} \\
\mathbf{3}\end{array}$ & $\begin{array}{l}\mathbf{O} \\
4\end{array}$ & $\begin{array}{l}\mathbf{O} \\
5\end{array}$ & $\begin{array}{l}\mathbf{E} \\
\mathbf{1}\end{array}$ & $\begin{array}{l}\mathbf{E} \\
2\end{array}$ & $\begin{array}{l}\mathbf{E} \\
\mathbf{3}\end{array}$ & $\begin{array}{l}E \\
4\end{array}$ & $\begin{array}{l}\mathbf{E} \\
\mathbf{5}\end{array}$ & $\begin{array}{l}\mathbf{E} \\
6\end{array}$ & $\begin{array}{l}\mathbf{E} \\
7\end{array}$ & $\begin{array}{l}\mathbf{E} \\
8\end{array}$ & $\begin{array}{c}\mathbf{M} \\
\mathbf{1}\end{array}$ & $\begin{array}{c}M \\
\mathbf{2}\end{array}$ & $\begin{array}{c}\mathbf{M} \\
\mathbf{3}\end{array}$ & $\begin{array}{c}M \\
4\end{array}$ \\
\hline Desorganização do projeto & & $\mathrm{X}$ & & & $\mathrm{X}$ & $\mathrm{X}$ & & $\mathrm{X}$ & $\mathrm{X}$ & & $\mathrm{X}$ & & $\mathrm{X}$ & $\mathrm{X}$ & $\mathrm{X}$ & $\mathrm{X}$ & $\mathrm{X}$ \\
\hline $\begin{array}{c}\text { Insegurança na realização } \\
\text { das atividades }\end{array}$ & & & $\mathrm{X}$ & $\mathrm{X}$ & & & & & & & & & & $\mathrm{X}$ & $\mathrm{X}$ & $\mathrm{X}$ & $\mathrm{X}$ \\
\hline $\begin{array}{c}\text { Falta de conhecimento pré- } \\
\text { vio para atuar com os alu- } \\
\text { nos }\end{array}$ & $\mathrm{X}$ & $\mathrm{X}$ & & & & $\mathrm{X}$ & $\mathrm{X}$ & & & & & $\mathrm{X}$ & $\mathrm{X}$ & & & & \\
\hline
\end{tabular}

A análise dos dados permitiu a identificação de alguns aspectos positivos e vários apontamentos negativos gerados pelas respostas dos alunos/observadores com relação ao projeto que participam. Foram entrevistados 05 observadores $(\mathrm{O})$, que são os próximos a realizarem intervenções no projeto, como estagiários. Todos eles expressaram que o projeto é 
um ambiente que oferece oportunidades únicas aos acadêmicos, principalmente para mudanças de concepções pessoais além de significar uma proposta de alto impacto social.

Dos pontos positivos, os observadores destacaram que o acompanhamento feito junto aos estagiários, por meio das observações das atividades desenvolvidas, tem sido fundamental para entenderem melhor as características das deficiências dos alunos atendidos, além de gerar maior proximidade com eles. Esse aspecto também facilita a próxima troca de "professor", que acontece no semestre seguinte. Pontuaram que as atividades monitoradas são indispensáveis, pois auxiliam na resolução das dificuldades que surgem durante a prática. E, enfatizaram que a elaboração de planejamentos e organização das aulas facilita o trabalho a ser desenvolvido com as pessoas com deficiência.

Dentre os pontos negativos destacados estão: a falta de organização do projeto nos aspectos de organização pessoal, já que alguns (O2, O5) apontaram que as monitoras e professores responsáveis pelo projeto poderiam estar mais presentes durante as atividades. Outros (O1, O2,) destacaram que o fato de terem grupos de alunos com limitações diferenciadas também dificulta o desenvolvimento das atividades e os objetivos a serem alcançados com elas, pois os conhecimentos a respeito das diferentes deficiências são limitados. Outro ponto negativo levantado pelos observadores 3 e 4 diz respeito à falta de incentivo para participação no projeto, que poderia ser dado pelo professor responsável pela disciplina exigida como pré-requisito. Isso porque para esses acadêmicos a disciplina de prérequisito não oferece subsídios suficientes para uma atuação direta com a população que frequenta o projeto de extensão, a ser realizada no período seguinte, devido à variedade de tipos de deficiência que o projeto atende e à falta de um conhecimento construído a respeito das mesmas. Segundo os depoimentos esse fator gera insegurança para atuarem com essa população.

É oportuno apoiarmo-nos nas afirmações de Martins e Batista (2006), para discutir esse primeiro ponto destacado pelos acadêmicos que ressaltam a importância de uma aplicação prática do tema estudado, mas questionam a forma como lhes é oferecida. Positiva ou negativamente, eles deram ênfase na questão do acompanhamento (tanto dos professores como dos monitores) nesse "tempo de observação", propiciando conhecimento necessário para futura intervenção. Os autores citados acima reforçam que:

A licenciatura defendida por nós é a que busca o conhecimento como forma de libertação de opressões, a que privilegia o trabalho com o ser humano que se movimenta sem referenciar-se apenas em padrões estéticos de beleza ou na perfeição da execução de movimentos; é a que propicia consciência corporal e vivências; nessa licenciatura, cooperação e participação, dentre outros, são fatores norteadores das discussões em sala de aula, preparando, assim, os futuros professores para a reflexão em torno desses valores. Neste sentido, faz-se fundamental que a tão propagada interação teoria e prática seja explicitada não apenas durante os embates teóricos, mas principalmente por meio de vivências que o aluno pode experienciar durante sua formação profissional. (MARTINS; BATISTA, 2006, p. 163)

Podemos afirmar que a atuação docente em um curso de formação de professores deve objetivar a oferta de embasamentos teórico-práticos para que os alunos possam compreender o significado de sua ação profissional. É preciso haver oportunidades de reflexão a respeito do perfil profissiográfico que se almeja construir, a partir de discussões teóricas somadas a uma vivência prática. 
Foram entrevistados 08 estagiários (E) que ao se referirem aos aspectos positivos declaram que essa experiência representa um momento de crescimento profissional e pessoal, além de poder contribuir com um dos fatores que permite às pessoas que frequentam o projeto melhorarem sua qualidade de vida.

Para alguns (E2, E5, E7, E8) a presença dos monitores lhes traz segurança no trabalho desenvolvido porque podem contar com um apoio extra na ocorrência de situações problema. Enfatizaram que a experiência oferece a ampliação de novos horizontes por permitir que suas intervenções aconteçam de forma adequada. Segundo eles, esse fato pode ser transferido para outras práticas pedagógicas a serem vividas na dimensão do trabalho da Educação Física com alunos que não possuem deficiência.

O discurso dos acadêmicos que destacam a importância da relação dessas vivências com outras práticas vinculadas à ação profissional nos faz refletir que o ato de ensinar experienciado com supervisão como atividade desenvolvida num curso, deve objetivar a multidisciplinaridade, trazendo aprendizado que pode ser aplicado em diversos contextos, conforme afirma Gimeno Sacristán (2000, p. 28):

A maioria das práticas pedagógicas tem a característica de estar multicontextualizada. As atividades práticas que servem para desenvolver os currículos estão sobrepostas em contextos alinhados uns dentro dos outros ou dissimulados entre si. O currículo se traduz em atividades e adquire significados concretos através delas. Esses contextos são produtos de tradições, valores e crenças muito assentadas, que mostram sua presença e obstinação à mudança quando uma proposta metodológica alternativa pretende instalar-se em certas condições já dadas.

Elogios também foram registrados em alguns discursos (E1, E2, E8) que afirmam positividade em todo o curso de Educação Física dessa Universidade, ressaltando sua estruturação. Mas também declaram que é uma área pouco valorizada pelos administradores e professores que compõem o curso.

Em relação aos pontos negativos levantados pelos alunos/estagiários, foram apontados, pelos E1, E3, E4, E6, E8: - o pouco tempo para a construção e aplicação de um planejamento que serve à organização da prática pedagógica, no qual constam informações importantes, tendo toda a estrutura documental disponibilizada; - a questão do número de professores que atuam nas intervenções, visando ao melhor relacionamento entre todos; - e ainda, os processos avaliativos.

Um fato importante a ser lembrado na construção das atividades é a maturidade dos alunos do curso diante do trabalho com pessoas que apresentam características tão específicas. Sobre isso, alguns acadêmicos (E1, E2, E7, E8) relatam que as dificuldades encontradas em situações problema poderiam ser superadas por si próprios, por meio da busca de informações e construções dos conhecimentos mais sólidos, sem esperarem informações trazidas pelos professores. Há diversos apontamentos expressados pelos acadêmicos, como pontos negativos, relacionados às questões da estrutura, organização e desenvolvimento das atividades práticas. $\mathrm{O}$ teor das respostas apontou certo distanciamento na relação aluno e professor nesse processo de formação, o que pode gerar dificuldade na maneira positiva de encarar as experiências e na própria segurança em exercer suas ações.

De acordo com Nóvoa (1991, p. 13) 
A troca de experiências oferece oportunidade de construção de saberes mútua, em que o professor é um formador e um formando, constantemente. As práticas de formação individualizadas favorecem a formação de perfil de professor que é mero transmissor de conhecimentos, produzidos fora de sua profissão. As práticas de formação coletivas favorecem o desenvolvimento de um saber mais reflexivo, em que estão envolvidos princípios e saberes muito mais valorativos.

Entendemos que os cursos devem dar maior importância nas relações interpessoais, nas quais acontecem as trocas de experiências entre professores formadores e acadêmicos, favorecendo cada vez mais reflexões no processo de formação inicial e continuada e valorizando a participação de todos os envolvidos.

Ao analisarmos as respostas das 04 monitoras, observamos que estas afirmam que as vivências de uma prática aplicada em sua formação inicial têm grande relevância para suas profissões como educadoras. Mas, reforçam que a falta de suporte, por parte dos professores, é algo que precisa ser repensado, ressaltando a necessidade de maior proximidade em suas supervisões para atuações mais seguras e efetivas dos acadêmicos.

Ao perspectivarmos mudanças na formação de professores, não se pretende implantar um modelo de ensino, mas refletir sobre os processos de aproximação teórico-prática da aprendizagem dos procedimentos metodológicos, e da importância que as experiências de múltiplas intervenções trazem à futura ação docente. Os componentes que integram uma formação inicial de um professor precisam se respaldar nos aspectos pessoais, socioculturais, científicos, tecnológicos, e técnicos em consonância com uma atuação futura. A teoria e prática devem andar juntas. O profissional deve conceber a ideia de que essa formação inicial é apenas o primeiro degrau de sua carreira e que a continuidade desse processo deve acontecer ao longo de toda sua prática docente (PACHECO, 2003).

Com relação à segunda pergunta feita aos voluntários da pesquisa, o quadro 2 apresenta as categorias apontadas na análise das respostas dos participantes a respeito do preparo que eles acreditam ter para atuar no projeto.

Quadro 2: Preparo dos acadêmicos para intervirem nas atividades realizadas.

\begin{tabular}{|c|c|c|c|c|c|c|c|c|c|c|c|c|c|c|c|c|c|}
\hline \multirow[t]{2}{*}{ CATEGORIAS } & \multicolumn{17}{|c|}{ VOLUNTÁRIOS (O - Observadores / E - Estagiários / M - Monitores } \\
\hline & $\begin{array}{l}\mathbf{O} \\
1\end{array}$ & $\begin{array}{l}O \\
2\end{array}$ & $\begin{array}{l}\mathbf{O} \\
3\end{array}$ & $\begin{array}{l}O \\
4\end{array}$ & $\begin{array}{l}O \\
5\end{array}$ & $\begin{array}{l}\mathbf{E} \\
\mathbf{1}\end{array}$ & $\begin{array}{l}\mathbf{E} \\
2\end{array}$ & $\begin{array}{l}\mathbf{E} \\
\mathbf{3}\end{array}$ & $\begin{array}{l}E \\
4\end{array}$ & $\begin{array}{l}\mathbf{E} \\
5\end{array}$ & $\begin{array}{l}E \\
6\end{array}$ & $\begin{array}{l}\mathrm{E} \\
7\end{array}$ & $\begin{array}{l}E \\
8\end{array}$ & $\begin{array}{l}\mathbf{M} \\
\mathbf{1}\end{array}$ & $\begin{array}{l}M \\
2\end{array}$ & $\begin{array}{l}\mathbf{M} \\
\mathbf{3}\end{array}$ & M4 \\
\hline Possui preparo & & & & & & & & & & & $\mathrm{X}$ & & $\mathrm{X}$ & & & & \\
\hline $\begin{array}{c}\text { Não possui pre- } \\
\text { paro }\end{array}$ & $\mathrm{X}$ & $\mathrm{X}$ & $\mathrm{X}$ & $\mathrm{X}$ & $\mathrm{X}$ & $\mathrm{X}$ & $\mathrm{X}$ & $\mathrm{X}$ & $\mathrm{X}$ & $\mathrm{X}$ & & $\mathrm{X}$ & & $\mathrm{X}$ & $\mathrm{X}$ & $\mathrm{X}$ & $\mathrm{X}$ \\
\hline $\begin{array}{l}\text { Preparo advindo } \\
\text { das disciplinas } \\
\text { biológicas do cor- } \\
\text { po humano }\end{array}$ & $\mathrm{X}$ & $\mathrm{X}$ & $\mathrm{X}$ & $\mathrm{X}$ & $\mathrm{X}$ & $\mathrm{X}$ & $X$ & $X$ & $X$ & $\mathrm{X}$ & $X$ & $\mathrm{X}$ & $X$ & $\mathrm{X}$ & $X$ & $\mathrm{X}$ & $X$ \\
\hline $\begin{array}{l}\text { A disciplina de } \\
\text { pré requisito não } \\
\text { oferece base }\end{array}$ & $X$ & X & $X$ & $X$ & & $X$ & $X$ & $X$ & $X$ & $\mathrm{X}$ & $X$ & $\mathrm{X}$ & $X$ & $\mathrm{X}$ & $X$ & $\mathrm{X}$ & $X$ \\
\hline
\end{tabular}

Segundo os acadêmicos que são observadores $(\mathrm{O})$ não há um preparo efetivo para atuarem no projeto, pois as disciplinas não oferecem suporte para isso, por serem praticamente desenvolvidas de maneira isolada de suas experiências reais. O conhecimento de- 
senvolvido em sala de aula não consegue estabelecer uma ligação como o conhecimento aprendido em suas vivências práticas. Isso é evidenciado principalmente na disciplina de prérequisito que para estes acadêmicos deveria ser a de maior embasamento para essa atuação, mas que, segundo os depoimentos, não oferece essa estrutura. Apenas um acadêmico (O5) afirmou que os conceitos dos tipos de deficiência aprendidos na disciplina foram esclarecedores, mas que a maneira como foram transmitidos não satisfaz a necessidade de aprendizagem de conhecimentos específicos para atuar. Todos os observadores declaram que as disciplinas de dimensão biológica, como fisiologia humana e do exercício, atingem esse objetivo, ofertando conhecimentos que eles conseguem perceber como fundamentais para intervirem na realidade, enquanto as de cunho pedagógico não têm dado conta de relacionar o aprendizado teórico com os aspectos necessários para a atuação como professor.

Essa é uma preocupação que tem sido discutida em cursos de formação de professores, em trabalhos apresentados em eventos científicos e em diferentes publicações, mas que não se repete apenas na área da Educação Física. São apontadas: a fragmentação dos conhecimentos desenvolvidos nas disciplinas, uma especialização precoce de temas básicos, o distanciamento entre o conhecimento desenvolvido nas Universidades com a realidade da prática profissional, além da falta de uma base pedagógica comum destinada à atuação desse futuro professor.

Um problema apontado por Pereira (1999), em estudo referente aos cursos de licenciatura, é a real percepção de disciplinas de cunho específico de determinada área se sobreporem às dimensões pedagógicas, sem haver relação estabelecida entre elas. As questões que tratam do ato de ensinar acontecem, na maioria das vezes, nos anos finais dos cursos, sem ligação com os demais conhecimentos adquiridos ao longo da formação. Atualmente, após 15 anos da detecção desse problema pelo autor, podemos afirmar que esse é um fator ainda presenciado.

Os estagiários (E) ao responderem as indagações a respeito do preparo que julgam ter para atuar com esse grupo de pessoas, também citam que as disciplinas pedagógicas estudadas não oferecem embasamento por serem ministradas de forma isolada, sem apresentarem uma relação da formação com a atuação do profissional de Educação Física, numa perspectiva mais ampla.

A disciplina específica no trato com pessoas com deficiências (pré-requisito) também foi citada por todos como dispensável e sem base norteadora por estar distante da realidade vivida nos momentos de suas intervenções.

Sabemos que os aspectos teórico-prático deveriam caminhar em consonância, o que poderia estimular maior participação dos alunos. Muitos estagiários alegam que a conscientização da importância dessa experiência poderia ser uma das preocupações da disciplina que propõe uma prática aplicada.

Em todos os discursos são mencionadas as disciplinas da dimensão biológica do curso como aquelas que oferecem maior conhecimento e mais segurança aos acadêmicos em suas futuras atuações profissionais. Para alguns acadêmicos (E6, E8) a organização curricular mostra-se equivocada, porque se as disciplinas que tratam de conhecimentos específicos para atuação com grupos especiais fossem ofertadas mais no início do curso, poderiam ter maior eficiência em suas ações.

O eixo que conduz a ampliação do conhecimento estruturado no desenrolar do currículo é um fator não muito discutido em publicações que tratam da formação de professores, permitindo que as instituições elaborem a ordem das disciplinas de acordo com suas disponibilidades, mesmo que atendam as diretrizes apresentadas nas normas impostas aos cursos de licenciatura. Há nos últimos semestres de alguns cursos de formação inicial, 
conforme pesquisa desenvolvida por Nista-Piccolo (2010), maior concentração de disciplinas consideradas básicas ao conhecimento pedagógico, ministradas simultaneamente a outras que aparecem de forma especializada.

Com relação ao embasamento teórico recebido durante a graduação, todas as monitoras (M1, M2, M3, M4) afirmam que as disciplinas não contemplam o necessário, que falta interesse dos professores do curso em realizarem um trabalho mais coeso, até mesmo para todas as vivências realizadas durante o curso, além da falta de material didático. E que aquelas que têm maior comprometimento com a formação profissional dos acadêmicos são as de anatomia, fisiologia, fisiologia do exercício, grupos especiais. A disciplina de pré-requisito também apareceu como isolada da disciplina de prática pedagógica, não sendo para as entrevistadas fundamental para a formação ou atuação com esse grupo de pessoas.

Sempre é preciso lembrar que as pessoas formadas no isolamento disciplinar perdem suas aptidões naturais para contextualizar os saberes necessários para a docência. Não perceber o global pode levar ao enfraquecimento da responsabilidade (MOREIRA; NISTA-PICCOLO, 2010, p. 78).

Esse ponto nos faz refletir a respeito da importância de um curso de formação acontecer de maneira consistente, bem orientada e com docentes que contribuam de forma eficiente e segura para futura atuação dos professores. Como a superficialidade temática tem acontecido em muitos cursos de licenciatura, as especializações têm ocupado o lugar dessa enorme lacuna existente na formação inicial.

As respostas dos acadêmicos com relação à contribuição da prática pedagógica para a formação profissional e pessoal são apresentadas no quadro 3, com as seguintes categorias identificadas:

Quadro 3: Contribuição da prática pedagógica na formação profissional e pessoal

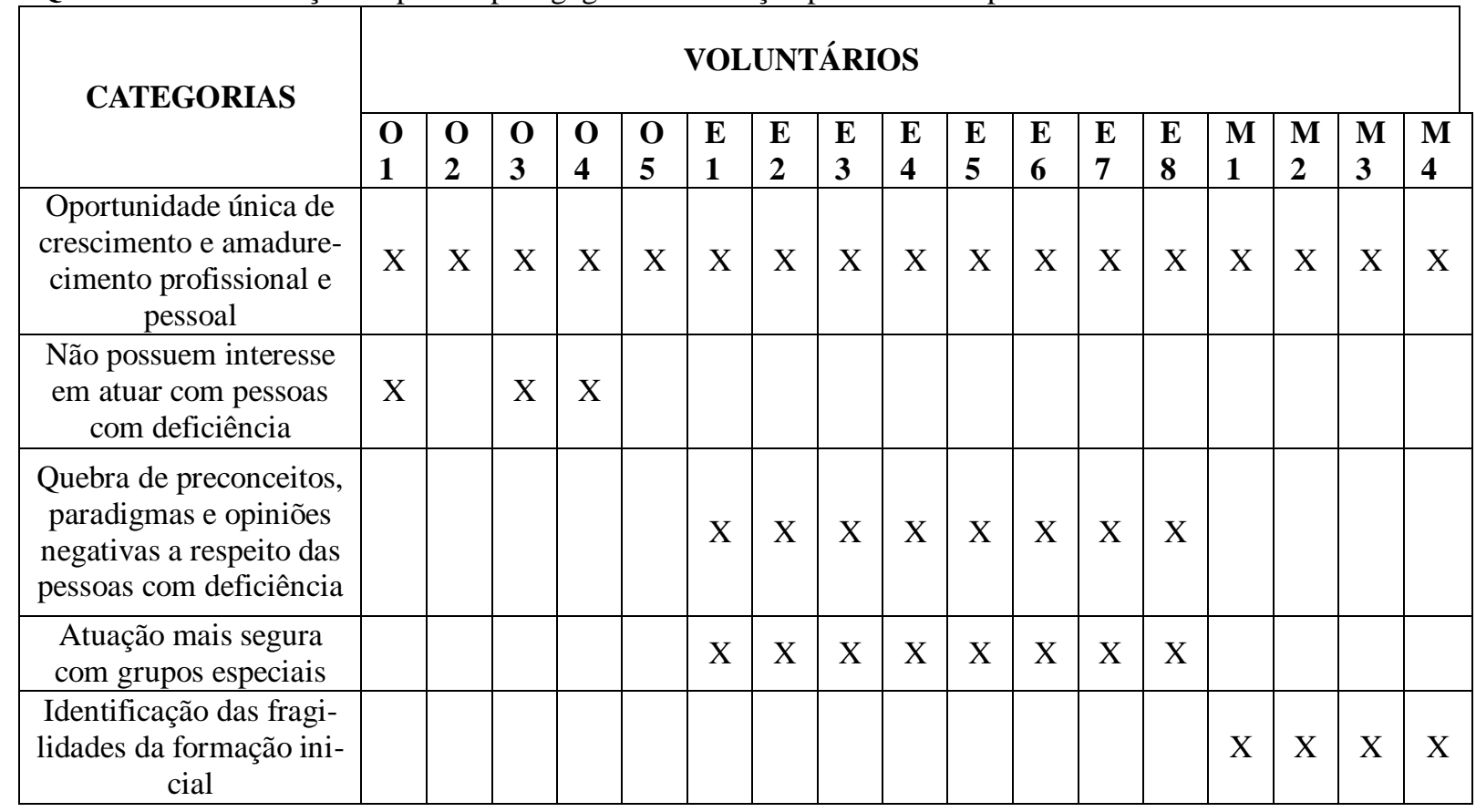

Os acadêmicos observadores destacaram a importância dessa prática pedagógica na formação pessoal/profissional apontando as vivências nesse projeto de extensão como a única 
oportunidade de intervirem com esse grupo de pessoas numa dimensão de aprendizagem. Mesmo assim, mais da metade dos futuros alunos/estagiários disseram que se essa participação fosse optativa, certamente eles não a realizariam.

Canário (2000), afirma que valorizar a experiência é saber aprender com ela, e não simplesmente imitar modelos vistos.

Percebe-se que há, por parte dos responsáveis, tanto pelas disciplinas como aqueles que organizam o projeto, certa superficialidade nessa aprendizagem voltada à formação de professores. É possível, portanto, que estes acadêmicos que declaram falta de vontade nessa participação, não tenham encontrado meios que os permitissem atribuir significado às vivências ou reconhecer conhecimentos necessários que podem advir delas.

No que se refere à contribuição da participação em um projeto de extensão, por meio das vivências nessa prática, para a formação profissional desses acadêmicos, os estagiários (E), em unanimidade, relataram a possibilidade de quebra de preconceitos com relação às pessoas com deficiência, pelas concepções e ideias negativas que traziam a respeito desse tipo de trabalho, afirmando que ao longo de suas experiências no projeto aprenderam a ver com mais normalidade o trato com essas pessoas. Essa afirmação promove um crescimento profissional na perspectiva de uma atuação voltada para a melhoria de um dos aspectos da qualidade de vida desse grupo. Percebem ainda um amadurecimento pessoal a partir da convivência com familiares das pessoas com deficiência, levando-os à maior compreensão dos problemas do dia a dia na questão de solidariedade ao próximo.

$\mathrm{O}$ ensino tem uma intencionalidade, persegue certos ideais e costuma ser praticado apoiando-se em conhecimentos sobre como funciona a realidade na qual intervém. Se é uma ação intencional, dirigida para algum fim, deve ter uma lógica, ainda que não existam planos absolutamente seguros nem se possa pensar num único caminho possível para desenvolvê-la (GIMENO SACRISTÁN, 1998, p. 199)

É fundamental a identificação de um crescimento pessoal pelos próprios acadêmicos, que pode refletir em suas trajetórias profissionais, permitindo a não fragmentação do ser humano, em questões profissionais e pessoais, em suas ações docentes.

Segundo as próprias monitoras essa experiência prática contribui muito para um entendimento sobre pessoas com deficiência. Mais ainda, isso permite que elas percebam com maior clareza as fragilidades que uma formação inicial oferece aos profissionais. Para atuar na área da Educação Física é preciso buscar maiores conhecimentos que subsidiem suas ações futuras, em qualquer das dimensões de atuação.

Visamos uma Educação Física una, quer seja ela Licenciatura ou Bacharelado que seja capaz de perceber e compreender o homem em movimento, suas quimeras, seus anseios e o torne livre, autônomo e capaz, desenvolvendo suas habilidades, capacidades motoras, respeitando as fases do desenvolvimento, suas limitações, unindo a teoria e a prática em um ambiente de integralidade, com o objetivo de proporcionar a construção de uma nova identidade nova para a área da Educação Física. (RIBEIRO, 2012, p. 51)

Desta forma, precisamos de mais contribuições dos aspectos axiológicos na formação de professores, de maneira que possam gerir crescimento profissional e amadurecimento pessoal voltados às ações que envolvem o ser humano. 


\title{
Considerações Finais
}

Acreditamos que analisar as percepções dos acadêmicos sobre os temas que norteiam a sua formação docente em Educação Física seja fundamental para construir diretrizes mais eficazes ao processo de formação de professores. Estudos e pesquisas que trazem dados que representam a realidade desses contextos precisam ser norte para possíveis transformações e modificações a serem realizadas nos cursos de licenciatura. Ouvir os próprios envolvidos nesse processo é uma forma de compreender as necessidades institucionais e as do mercado de trabalho, vislumbrando melhor qualidade do ensino em suas formações docentes, permitindo assim, atuações futuras mais eficazes.

\section{THE PERCEPTION OF FUTURE PHYSICAL EDUCATION TEACHERS ON THE PREPARATION IN WORKING WITH PEOPLE WITH DISABILITIES}

\begin{abstract}
In this study we seek to identify aspects that influence positively and negatively in future Physical Education teacher's performance, regarding the perceptions of academics about the preparation in the development of practical activities developed in an extension project which assists people with disabilities. It was possible to perceive that there is a gap between what's worked in the curricular disciplines and practices experienced in initial formation. The decontextualisation of the curricular structure of the course, evidenced in the speeches of future teachers, points out the need for reflections about a reorganization of the curriculum of teacher training courses in the area and its implications on professional performance.

Key-words: Training of teachers. Graduate courses. Professional performance.

\section{LA PERCEPCIÓN DE PROFESORES DE EDUCACIÓN FÍSICA FUTURA SOBRE LA PREPARACIÓN EN EL TRABAJO CON PERSONAS CON DISCAPACIDAD}

Resumen: En este estudio pretendemos identificar los aspectos que influyen positivamente y negativamente en el futuro desempeño del profesor de educación física, con respecto a las percepciones de los académicos con respecto a la preparación en el desarrollo de actividades prácticas se convirtió en un proyecto de extensión que ayuda a las personas con discapacidad. Fue posible percibir que existe una brecha entre lo que se trabaja en las disciplinas curriculares y prácticas en la formación inicial. La descontextualización de la estructura curricular del curso, que se evidencia en los discursos de los futuros profesores, señala la necesidad de reflexiones sobre una reorganización del currículo de cursos de formación docente en el área y sus implicaciones en el desempeño profesional.

Palabras-Claves: Formación del profesorado. Cursos de grado. Desempeño profesional.

\section{Referências}

ARAÚJO, D. Noção de Competência e organização curricular. Revista Baiana de Saúde Pública, v. 31, Supl. 1, p. 32-43, jun. 2007.

BRASIL. Ministério da Educação. Conselho Nacional de Educação. Conselho Pleno. Resolução CNE/ CP 2, de 04 março de 2002: Institui a duração da carga horária dos cursos de licenciatura, de graduação plena, de formação de professores da Educação Básica em nível superior. Brasília, DF, 2002. 
CANÁRIO, R. A prática profissional na formação de professores. Universidade de Lisboa. Formação Profissional de professores no ensino superior. Universidade de Aveiro, 2000.

FORMOSINHO, J.; MACHADO, J. Currículo e Organização: as equipas educativas como modelo de organização pedagógica. Currículo sem Fronteiras, v. 8, n. 1, pp. 5-16, Jan/Jun 2008.

FRAUCHES, C. C. (Org.). Diretrizes Curriculares para os cursos de graduação. Brasília: ABMES Editora, 2008.

GAMA, M. E. R.; TERRAZZAN, E. A. Formação pedagógica: desafios da organização curricular em curso de licenciatura. Educação \& Linguagem, v. 16, n. 1, p. 249-265, jan.jun. 2013.

GIMENO SACRISTÁN, J. Aproximação ao conceito de um currículo. In: GIMENO SACRISTÁN, J. O currículo: uma reflexão sobre a prática. 3. ed. Porto Alegre: Artmed, 2000.p. 14-53.

GIMENO SACRISTÁN, J. Plano do currículo, plano do ensino: o papel dos professores/as. In: GIMENO SACRSITÁN, J.; PÉREZ GÓMEZ, A. I. Compreender e transformar o ensino. 4. ed. São Paulo: Artmed, 1998. p.197-231.

LAVILLE, C.; DIONNE, J. A construção do saber: manual de metodologia da pesquisa em ciências humanas. Tradução Heloísa Monteiro e Francisco Séttineri. Porto Alegre, Artes Médicas Sul Ltda, 1999.

MARTINS, I.C.; BATISTA, J. C. F. Educação Física, formação e prática profissional. In: DE MARCO, A. (Org.). Educação Física: Cultura e Sociedade. 2. ed. Campinas, SP: Papirus, 2006. p. 157-170.

MELLO, G. N. Formação Inicial de professores para a educação básica: uma revisão radical. São Paulo em perspectiva, 14(1) 2000.

MOREIRA, A. F. B. Em busca da autonomia docente nas práticas curriculares no Brasil. In: OLIVEIRA, M. R. N. S.; PACHECO, J. A. (Orgs.). Currículo, didática e formação de professores. Campinas, SP: Papirus, 2013. p. 69-96.

MOREIRA, E. C.; TOJAL, J. B. A. G. A formação em Programas de Pós-Graduação Strictu Sensu em Educação Física: preparação docente versus preparação para pesquisa. Movimento, Porto Alegre, v. 15, n. 04, p. 127-145, outubro/dezembro de 2009.

MOREIRA, W. W.; NISTA-PICCOLO, V. L. Formação de Professores de Educação Física e o Projeto Pedagógico da Escola: a busca do pensamento complexo. In: Bento, J. O.; Tani, G; Prista, A. (Orgs.) Desporto e educação física em português. Universidade do Porto. Porto, Portugal: Multimena, 2010. p. 75-83. 
NISTA-PICCOLO, V. L. Prolegômenos de uma pesquisa sobre o perfil do professor de Educação Física. Revista Brasileira de Docência, Ensino e Pesquisa em Educação Física. Vol. 2, n. 1, p. 111-125, Julho/2010.

NISTA-PICCOLO, V. L.; MOREIRA, W.W. Esporte para a saúde nos anos finais do ensino fundamental. São Paulo: Cortez, 2012.

PACHECO, J. A. Formação de professores. [documento de discussão]. Universidade do Minho, 2003.

PEREIRA, J. E. D. As licenciaturas e as novas políticas educacionais para a formação docente. Educação \& Sociedade, ano XX, nº 68, Dezembro/99.

RIBEIRO, D. B. G. Licenciatura e Bacharelado: a formação profissional na área da Educação Física. 2012. 104 f. Dissertação (mestrado em Educação Física) - Programa de PósGraduação em Educação Física, Universidade Federal do Triângulo Mineiro, Uberaba, 2012.

ROLDÃO, M.C. Gestão Curricular - Fundamentos e Práticas. ME-DEB, 1999. TOJAL, J. B. Corpo ativo e preparação profissional. In: MOREIRA, W.W. (Org.). Século XXI: a era do corpo ativo. Campinas, SP: Papirus, 2006. p.235-253.

Recebido em: 07/11/2014

Revisado em: 07/02/2015

Aprovado em: 25/02/2015

Endereço para correspondência:

vicksobreira@yahoo.com.br

Vickele Sobreira

Universidade Federal do Triângulo Mineiro

Av.Frei Paulino, 30 - Bairro Abadia

CEP: 38025-180 Uberaba/MG 